\title{
Pharmacology of Glutamate Neurotoxicity in Cortical Cell Culture: Attenuation by NMDA Antagonists
}

\author{
Dennis W. Choi, Jae-young Koh, and Stephen Peters \\ Department of Neurology, Stanford University Medical Center, Stanford, California 94305
}

The antagonist pharmacology of glutamate neurotoxicity was quantitatively examined in murine cortical cell cultures. Addition of 1-3 mM DL-2-amino-5-phosphonovalerate (APV), or its active isomer D-APV, acutely to the exposure solution selectively blocked the neuroexcitation and neuronal cell loss produced by $\boldsymbol{N}$-methyl-D-aspartate (NMDA), with relatively little effect on that produced by either kainate or quisqualate. As expected, this selective NMDA receptor blockade only partially reduced the neuroexcitation or acute neuronal swelling produced by the broad-spectrum agonist glutamate; surprisingly, however, this blockade was sufficient to reduce glutamate-induced neuronal cell loss markedly.

Lower concentrations of APV or D-APV had much less protective effect, suggesting that the blockade of a large number of NMDA receptors was required to acutely antagonize glutamate neurotoxicity. This requirement may be caused by the amplification of small amounts of acute glutamate-induced injury by subsequent release of endogenous NMDA agonists from injured neurons, as the "late" addition of 10-1000 $\mu \mathrm{M}$ APV or D-APV (after termination of glutamate exposure) also reduced resultant neuronal damage. If APV or D-APV were present both during and after glutamate exposure, a summation dose-protection relationship was obtained, showing substantial protective efficacy at low micromolar antagonist concentrations. Screening of several other excitatory amino acid antagonists confirmed that the ability to antagonize glutamate neurotoxicity might correlate with ability to block NMDA-induced neuroexcitation: The reported NMDA antagonists ketamine and DL-2-amino-7-phosphonoheptanoate, as well as the broad-spectrum antagonist kynurenate, were all found to attenuate glutamate neurotoxicity substantially; whereas gamma-D-glutamylaminomethyl sulfonate and L-glutamate diethyl ester, compounds reported to block predominantly quisqualate or kainate receptors, did not affect glutamate neurotoxicity.

The present study suggests that glutamate neurotoxicity may be predominantly mediated by the activation of the NMDA subclass of glutamate receptors-occurring both directly, during exposure to exogenous compound, and indirectly,

\footnotetext{
Received Jan. 29, 1987; revised May 11, 1987; accepted July 17, 1978.

We thank M. Yokoyama and V. Viseskul for technical assistance. This work was supported by NIH Grants NS2 1628 and NS12151.S.P. is supported by NIH Training Grant NSO7280; D.W.C. is a recipient of a Hartford Fellowship from the John A. Hartford Foundation.

Correspondence should be addressed to Dennis W. Choi, C-338, Department of Neurology, Stanford University Medical Center, Stanford, CA 94305.

Copyright (C) 1988 Society for Neuroscience $0270-6474 / 88 / 010185-12 \$ 02.00 / 0$
}

due to the subsequent release of endogenous NMDA agonists. Given other studies linking NMDA receptors to channels with unusually high calcium permeability, this suggestion is consistent with previous data showing that glutamate neurotoxicity depends heavily on extracellular calcium.

The central neurotoxicity (Lucas and Newhouse, 1957; Olney, 1969) of the putative excitatory amino acid neurotransmitter glutamate has been postulated to contribute to the central neuronal cell loss associated with several neurological disease states (Coyle et al., 1981; Schwarcz and Meldrum, 1985; Rothman and Olney, 1986). Under acute disease conditions characterized by some combination of cellular injury, neuronal depolarization, and impaired energy metabolism - for example, hypoxia (Rothman, 1984), hypoglycemia (Wieloch, 1985), or prolonged seizures (Nadler et al., 1978; Sloviter, 1983)-increased synaptic release and reduced cellular uptake may conspire to produce rapidly toxic extracellular glutamate concentrations (Benveniste et al., 1984; Hagberg et al., 1985). More subtle alterations in the glutamate system, for example, abnormal glutamate metabolism, have been postulated to underlie the slow neuronal loss of certain chronic ncurodegenerative discases (McGecr and McGeer, 1976; Olney and De Gubareff, 1978; Plaitakis et al., 1982; DeBoni and McLachlan, 1985).

The mechanisms by which excess exposure to glutamate can lead to this potentially important neuronal cell injury are not well understood and depend considerably on extrapolation from the better defined phenomenon of glutamate neuroexcitation. Several studies of the pharmacology of glutamate neuroexcitation have suggested that it is mediated by action on perhaps 3 subclasses of postsynaptic receptors, each named by a defining selective agonist: $N$-methyl-D-aspartate (NMDA), quisqualate (QUIS), and kainate (KAIN) (Watkins and Evans, 1981; Foster and Fagg, 1984). The NMDA subclass is the best characterized, in part due to the availability of selective antagonists, such as DL-2-amino-5-phosphonovalerate (APV) (Davies et al., 1981). NMDA-activated membrane channels are thought to exhibit a number of special properties, including susceptibility to blockade by magnesium at hyperpolarized membrane potentials (Mayer et al., 1984; Nowak et al., 1984), rapid desensitization (Zorumski and Fischbach, 1985), and high calcium permeability (MacDermott et al., 1986; Mayer et al., 1986). Although glutamate has a high affinity for the NMDA receptor (Olverman et al., 1984), magnesium blockade (at least near resting membrane potentials) and desensitization probably act to limit the contribution of NMDA channels, relative to that of QUIS and KAIN channels, to glutamate neuroexcitation. Glutamate neuroexcitation is thus completely blocked by high concentrations 
of broad spectrum antagonists such as kynurenate (Ganong et al., 1983; Jahr and Jessel, 1985; Huettner and Baughman, 1986) but is only partially attenuated by selective NMDA antagonists (Watkins and Evans, 1981; Mayer and Westbrook, 1984; O'Brien and Fischbach, 1986).

The corresponding antagonist pharmacology of glutamate neurotoxicity (GNT) has not becn systematically studied in a direct fashion, in large part because GNT is difficult to study in the intact nervous system. The ubiquitous presence of rapid glutamate uptake makes it difficult to administer sufficient compound exogenously to achieve toxic extracellular concentrations in vivo (Olney, 1978; Mangano and Schwarcz, 1983); even in brain slice preparations, cellular uptake may attenuate glutamate delivery by more than 2 orders of magnitude (Garthwaite, 1985). One previous study in hippocampal cultures has demonstrated that $10 \mathrm{~mm}$ concentrations of the broad-spectrum (Huettner and Baughman, 1986) antagonist gamma-D-glutamylglycine could block GNT (Rothman, 1984). Further knowledge of the antagonist pharmacology of GNT would likely be valuable, not only as a key point of comparison between GNT and glutamate neuroexcitation, but also as a possible basis for developing strategies directed toward reducing neuronal injury in the clinical arena.

We have initiated an investigation of GNT in dissociated murine neocortical cell cultures, where glutamate is a potent and rapidly acting neurotoxin (Choi et al., 1987a). In the present study, we quantitatively investigated the ability of defined concentrations of several excitatory amino acid antagonists to block GNT in these cultures. Since GNT is likely dependent largely on a calcium influx (Choi, 1985; Garthwaite and Garthwaite, 1986; Rothman et al., 1986), and NMDA-activated channeis are more permeable to calcium than QUIS or KAIN channels (see above), we began the study with the hypothesis (Choi, 1987) that a selective blockade of NMDA receptors might disproportionately attenuate GNT. Preliminary accounts of our study (Choi et al., 1986), as well as of a relevant study in hippocampal cultures (Rothman et al., 1986), have been published.

\section{Materials and Methods}

Cortical cell culture. Mixed cortical cell cultures, containing both neuronal and glial elements, were prepared generally as previously described (Choi et al., 1987a) from fetal mice at 14-17 d gestation. Dissociated cortical cells were plated in Primaria (Falcon) $35 \mathrm{~mm}$ dishes $\left(10^{6}\right.$ cells/ dish), or $15 \mathrm{~mm}$ multiwell vessels $\left(2.8 \times 10^{5}\right.$ cells/well $)$ in Eagle's minimal essential medium (MEM-Earle's salts) supplemented with $10 \%$ heat-inactivated horse serum, $10 \%$ fetal bovine serum, glutamine $(2$ $\mathrm{mm})$, and glucose $(21 \mathrm{~mm})$. Cultures were kept at $37^{\circ} \mathrm{C}$ in a humidified $\mathrm{CO}_{2}$ atmosphere (pH 7.2). After 5-10 d in vitro, non-neuronal cell division was halted by $1-3 \mathrm{~d}$ of exposure to $10^{-5} \mathrm{M}$ cytosine arabinoside, and the cells were shifted into a maintenance medium identical to the plating media, but lacking fetal serum. Subsequent media replacement was carried out twice per week. Only mature (15-24 d in vitro) cortical cultures were selected for study; whenever possible, comparisons were made on matched sister cultures derived from a single plating.

Glutamate exposure. Exposure to glutamate, either alone or in the presence of antagonist drugs, was carried out at room temperature in a Tris-buffered "control salt solution" (CSS), substituted for culture medium by triple exchange; CSS had the following composition (in $\mathrm{mM}$ ): $\mathrm{NaCl}, 120 ; \mathrm{KCl}, 5.4 ; \mathrm{MgCl}_{2}, 0.8 ; \mathrm{CaCl}_{2}, 1.8 ;$ Tris- $\mathrm{Cl}\left(\mathrm{pH} 7.4\right.$ at $\left.25^{\circ} \mathrm{C}\right)$, 25; glucose, 15. After $5 \mathrm{~min}$, the exposure solution was washed out thoroughly $(>1000$-fold dilution in all cases, and $>10,000$-fold dilution in the acute APV experiments) and replaced with another defined solution (free of glutamate or lactate dehydrogenase)-Eagle's MEM with augmented glucose $(25 \mathrm{~mm})$ - prior to returning the dishes to the $37^{\circ} \mathrm{C}$ incubator. Control experiments showed that little or no cortical cell damage was produced by this protocol if glutamate was omitted.
Assessment of cellular injury. Neuronal cell injury was assessed in all experiments by examination of cultures with phase-contrast microscopy at $100-400 \times$. This examination was usually performed $1 \mathrm{~d}$ after exposure to glutamate, at which point the process of cell death was largely complete; previous experience has suggested that glutamate-induced injury of cultured cortical neurons and glia can be reliably estimated in this fashion (Choi et al., 1987a). In some experiments, phase-contrast examination was augmented by subsequent bright-field examination of trypan blue staining $(0.4 \%$ for $5 \mathrm{~min})$, a dye staining debris and nonviable cells. For illustrative purposes, representative $200 \times$ microscope fields, marked with an objective marker, were photographed both before and $1 \mathrm{~d}$ after exposure to glutamate.

In most experiments, the morphological estimate of cell injury was confirmed by the measurement of lactate dehydrogenase (LDH), released by damaged or destroyed cells, in the extracellular fluid $1 \mathrm{~d}$ after glutamate exposure; this convenient and quantitative index invariably correlated with the morphological estimate. LDH was mcasured at room temperature using the method of Wroblewski and LaDue (1955). Samples of media $(0.2 \mathrm{ml})$ were added to $2.3 \mu \mathrm{M}$ of sodium pyruvate in 0.1 $\mathrm{M} \mathrm{KH} \mathrm{PO}_{4}$ buffer (pH 7.5 at $25^{\circ} \mathrm{C}$ ) with $0.2 \mathrm{mg}$ of added NADH (total volume, $3 \mathrm{ml}$ ). The absorbance of the reaction mixture at $340 \mathrm{~nm}$, an index of NADH concentration, was measured with a spectrophotometer and recorded automatically at $2 \mathrm{sec}$ intervals using a Metrabyte dataacquisition board linked to an IBM PC microcomputer. LDH concentration was then automatically calculated from the slope of the absorbance curve (fit by linear regression to the linear initial portion of the curve and corrected for temperature and light path). Accuracy of the assay was verified by periodic checks of a standard LDH enzyme solution (Sigma Enzyme Control 2-E).

A small amount of LDH was always present in the media of cultures carried though the exposure protocol but without addition of glutamate. This background amount, determined on sister cultures within each experiment, was subtracted from values obtained in treated cultures. A series of control experiments, described elsewhere (Koh and Choi, 1987), showed that the specific efflux of LDH induced by glutamate exposure (after background subtraction) was linearly proportional to the number of neurons damaged or destroyed and that no specific LDH efflux occurred when pure cultures of cortical glia were similarly exposed to glutamate.

Acute "excitotoxic" neuronal swelling per se, without late cell injury (for example, produced by brief kainate exposure), did not appear to produce much LDH efflux and was difficult to make a comparative assessment by simple visual inspection. Therefore, a quantitative index was devised, representing the mean increase in cell body area sustained by a series of 50-100 ncurons during 15-30 min of exposure to neurotoxic amino acids. Cell areas were measured directly on tracings of before-and-after photographs taken under bright-field optics (which gave better definition of cell outlines than phase optics-see Fig. 5, top) with the aid of a digitizing tablet and a microcomputer. Only neurons with distinct cell outlines were included in the measurements, and the change in the area of each neuron was expressed as a percentage of its baseline area.

Electrophysiology. Dishes were maintained on the stage of an inverted Nikon Diaphot microscope, in a warmed aluminum block (bath temperature, $33^{\circ} \mathrm{C}$ ), and perfused continuously with a recording medium with the following composition (in $\mathrm{mm}$ ): $\mathrm{Na}, 130 ; \mathrm{K}, 5.4 ; \mathrm{Ca}, 4 ; \mathrm{Mg}$, $0.8 ; \mathrm{Cl}, 145$; glucose, 15 ; HEPES, 10 ; TTX $(1 \mu \mathrm{M})$ was added routinely to reduce interference from spontaneous synaptic activity. Intracellular recordings were made from individual ncurons under direct visual guidance, using $4 \mathrm{M}$ potassium acetate-filled microelectrodes (40-100 M $\Omega$ ); current was passed through the recording electrode by means of a standard bridge circuit. Only neurons with stable resting potentials $<-50$ $\mathrm{mV}$, and an input time constant permitting unequivocal balancing of the bridge circuit, were included in the study. Defined concentrations of drugs were delivered to cells by pressure ejection from a nearby "puffer" pipette, using the recording medium as a drug carrier (Choi and Fischbach, 1981).

Drugs. DL-2-amino-5-phosphonovalerate (APV) and its D-isomer (DAPV), as well as $\gamma$-D-glutamylaminomethyl sulfonate (GAMS), were obtained from Tocris Neuramin. DL-2-amino-7-phosphonoheptanoate (APH), DL-2-amino-4-phosphonobutyrate (APB), DL-2-amino-3-phosphonopropionate (APP), $\gamma$-D-glutamylglycine (DGG), and ( \pm )-cis-2,3piperidinc dicarboxylate (PDA) (trans-free) were obtained from Cambridge Research Biochemicals. DL-Ketamine was a kind gift of WarnerLambert. L-Glutamate diethyl ester (GDEE), D- $\alpha$-aminoadipate (DAA), and kynurenate (KYN), were obtained from Sigma. 

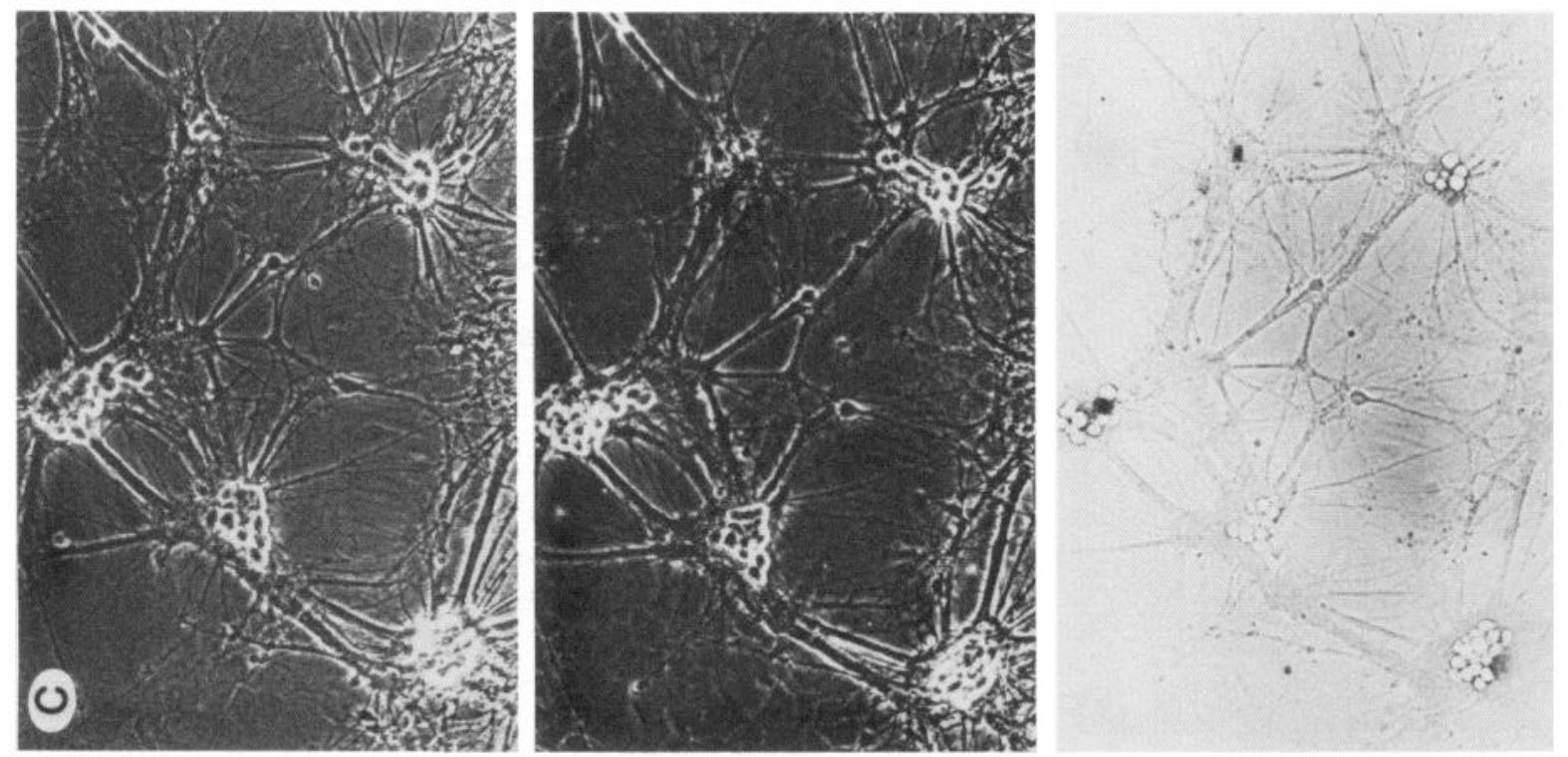

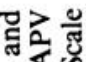

जิ

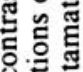

可灵

행

ठ०

50

5.

흘

응.

을

氜

ง.

है

践

究
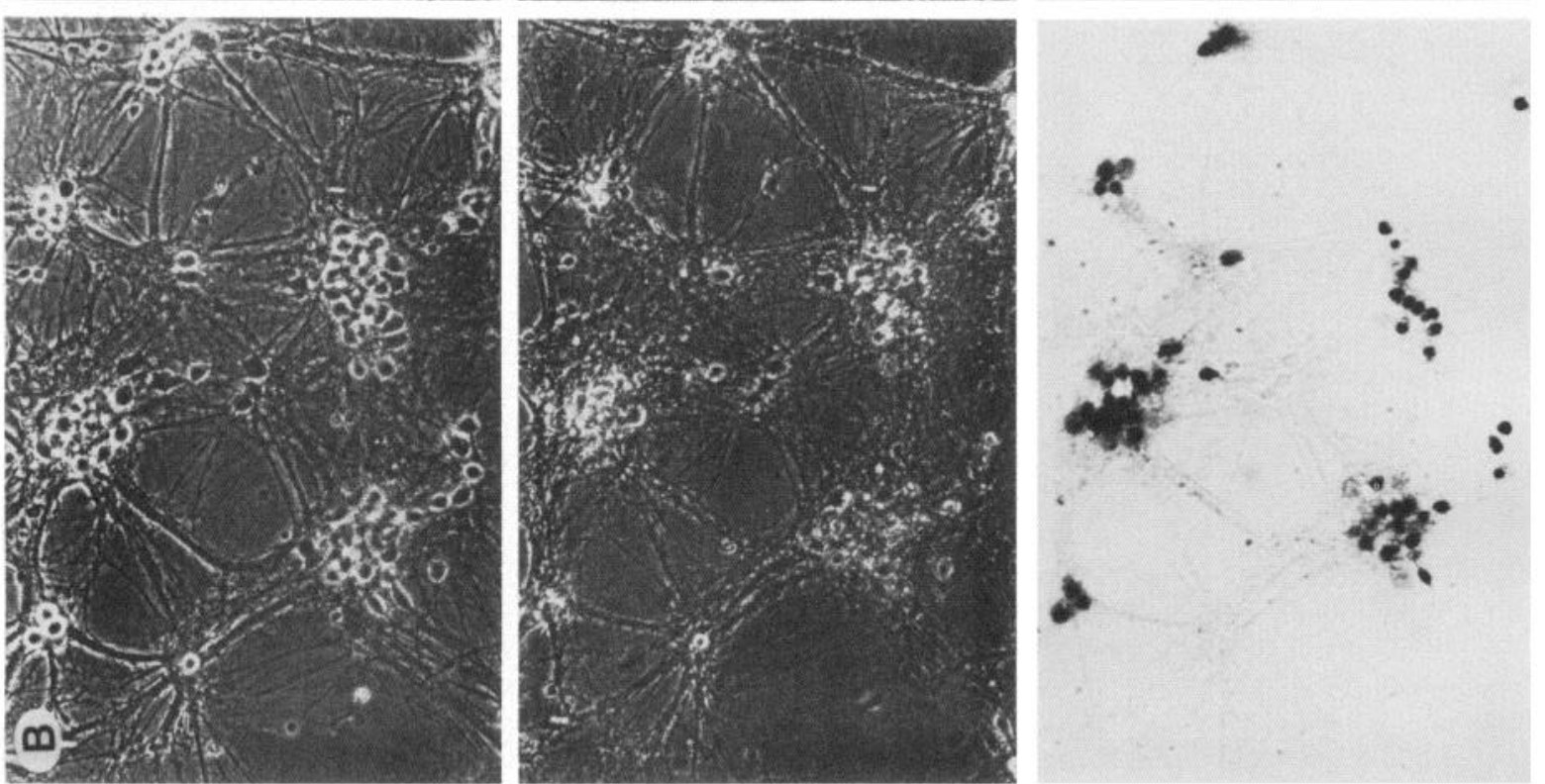

总

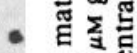

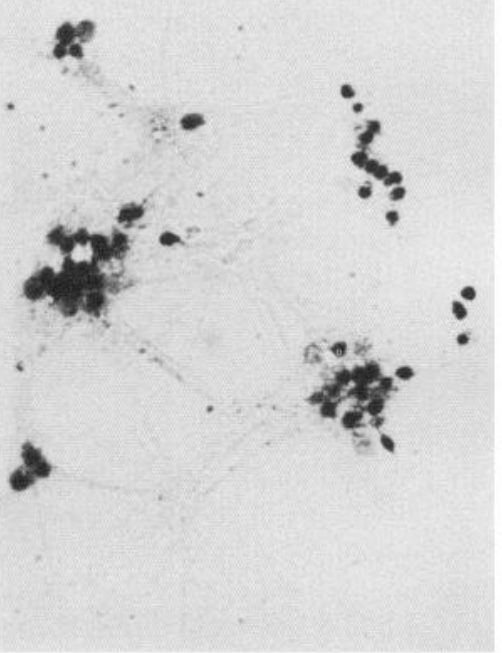

ㅍㅇㄷㄷ

ㄷㅇㅇ

氙

तु 这

区ᄒ

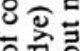

늘

- 远

达

है?

도

을

동근

煰.

논

है
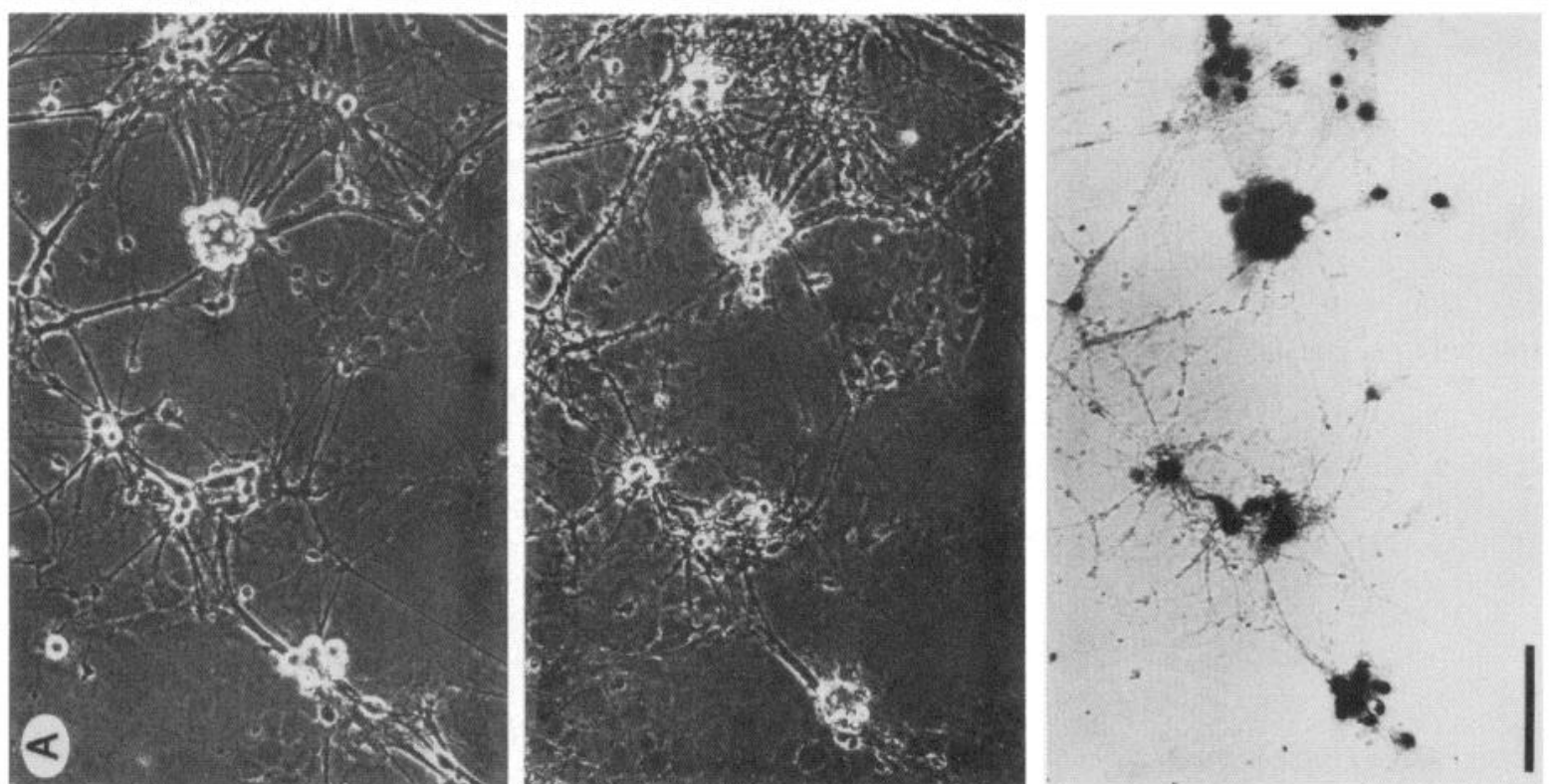

뭉 로

웅

柴的

들

ํํㄹ

닐응

호

항

혼

\%

号

줌응

ปิ

$>$ จิ

《롤

-

웡용

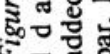




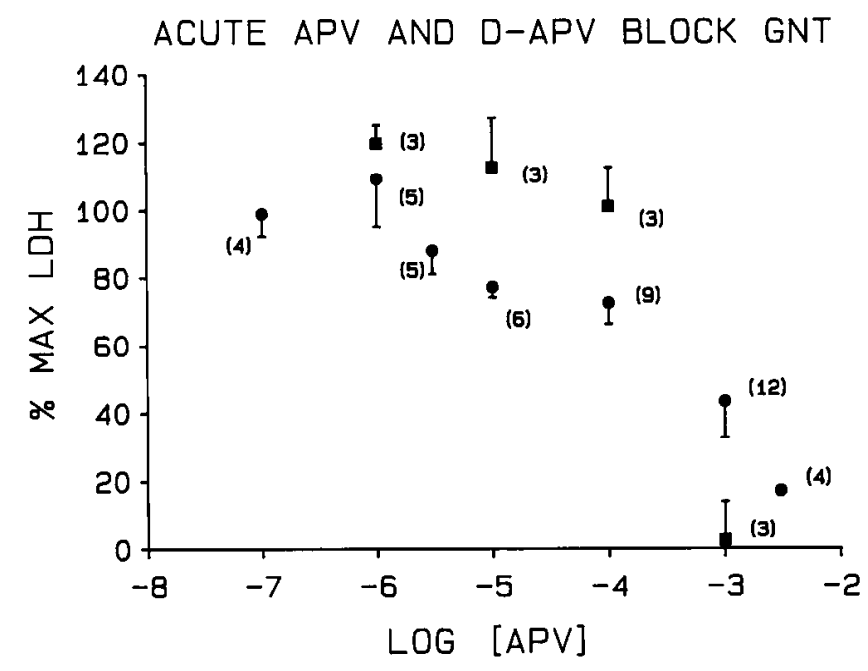

Figure 2. Acute APV and D-APV dose-protection curves. In a number of experiments pooled together here, cultures were exposed to $500 \mu \mathrm{M}$ glutamate for $5 \mathrm{~min}$, with the indicated concentrations of either APV (circles) or D-APV (squares) present acutely during the glutamate exposure. The amount of LDH present in the bathing medium the following day is shown (mean \pm SEM, number of cultures specified in parentheses for each point) and serves as an index of resultant neuronal injury. LDH values in this and subsequent figures have been corrected for background release as described in Materials and Methods, and are scaled to the amount of LDH found in matched sister control cultures exposed to glutamate with no antagonist present $(=100)$. Little protective effect is evident with either APV or D-APV below $1 \mathrm{~mm}$, but a large protective effect is seen at 1-3 mM concentrations. The small differences between the protection produced by APV and by D-APV at concentrations of 1,10 , and $100 \mu \mathrm{M}$ are not significant ( $p>0.05$, analysis of variance and Student-Newman-Keuls' test).

\section{Results}

As previously reported, exposure of mature (15-24 $\mathrm{d}$ in vitro) cortical cell cultures to $500 \mu \mathrm{M}$ glutamate for $5 \mathrm{~min}$ resulted by the following day in widespread neuronal disintegration (Choi et al., 1987a). Addition of the established selective NMDA antagonist APV to the acute exposure solution at concentrations of 1-3 mM (Fig. 1C), but not lower (Fig. 1, $A, B$ ), substantially attenuated GNT. The threshold concentration appeared to be $1 \mathrm{~mm}$, producing near complete block of GNT in several experiments (Fig. 1C) but only partial attenuation in others; $3 \mathrm{~mm}$ APV reliably produced marked attenuation of GNT ( 8 trials). In many experiments, qualitative morphological assessment of GNT was corroborated by measurement of LDH in the bathing medium $1 \mathrm{~d}$ after glutamate exposure (Fig. 2).

The NMDA antagonist activity of APV, a racemate, resides predominantly in its D-isomer (D-APV); the L-isomer probably has only minimal NMDA antagonist activity (Stone et al., 1981; Davies and Watkins, 1982). We therefore tested the ability of D-APV alone to antagonize GNT acutely, and we found a concentration-effect relationship similar to that found with the racemate (perhaps slightly more effective at high concentrations, consistent with the inherent 2 -fold increase in active isomer over the racemate) (Fig. 2).

The ability of APV and D-APV to antagonize GNT acutely was consistent with the hypothesis that GNT was largely dependent on events linked to NMDA receptor activation. Although 20-50 $\mu \mathrm{M}$ concentrations have been found sufficient to substantially attenuate the neuroexcitatory action of 50-100 $\mu \mathrm{M}$ NMDA on layer $V$ visual cortical neurons (Huettner and Baugh- man, 1986), the observed requirement for millimolar concentrations to block GNT seemed justifiable on the basis of the competitive nature of APV antagonism and the high concentrations of glutamate used. Supporting that possibility, we have found that an APV concentration of $1 \mathrm{~mm}$ is required for near complete blockade of the neuroexcitatory effect of high $(500 \mu \mathrm{M})$ concentrations of NMDA itself in our cortical cultures (S. Peters and D. W. Choi, unpublished observations; also see Fig. 3). O'Brien and Fischbach (1986) also found $1 \mathrm{mM}$ APV necessary to effect blockade of NMDA receptors on chick motoneurons from high concentrations of NMDA or glutamate.

An alternative possibility, that millimolar concentrations of APV and D-APV were capable of producing a nonselective block of both NMDA and non-NMDA (KAIN and QUIS) receptors, was directly examined using electrophysiological techniques. Pressure ejection of $500 \mu \mathrm{M}$ glutamate, $500 \mu \mathrm{M}$ NMDA, $500 \mu \mathrm{M}$ KAIN, or $50 \mu \mathrm{M}$ QUIS onto cortical neurons impaled for intracellular recording invariably produced brisk depolarizing responses associated with increases in membrane conductance, except in the case of NMDA, which with smaller responses exhibited apparent reductions in membrane conductance (Mayer et al., 1984; Nowak et al., 1984). To minimize dilution, APV and D-APV were delivered by pressure ejection both beforc and during delivery of these agonists, and any resultant reduction in agonist response amplitude was expressed as a percentage of the peak baseline response in the same neuron. APV, $1 \mathrm{~mm}$, was found to be a potent and highly selective NMDA antagonist, producing no effect on QUIS responses, and only minimal depression of KAIN responses (Fig. 3). D-APV, 2 mM, was, as expected, a slightly more complete NMDA antagonist than 1 mM APV, but it also produced some KAIN depression and slight QUIS depression (Fig. 3). Consistent with action of glutamate on both NMDA and non-NMDA receptors, neither $1 \mathrm{mM}$ APV nor $2 \mathrm{mM}$ D-APV produced more than half attenuation of glutamate responses (Fig. 3).

We have previously shown that the neurotoxicity of glutamate on cortical neurons can be separated into 2 components on the basis of differences in time course and ionic dependence: an carly component, marked by acute neuronal swelling and dependent on the presence of extracellular sodium; and a late component, marked by delayed neuronal disintegration and dependent on the presence of extracellular calcium (Choi, 1987). Under conditions of brief glutamate exposure, the latter component dominates, and blockade of the former component is not required to markedly increase neuronal survival (Choi, 1987). If early neuronal swelling in fact reflects the "excitotoxic" entry of sodium through glutamate-opened membrane channels, with associated entry of chloride and water (Olney et al., 1971, 1986; Rothman, 1985; Choi, 1987), one would predict that this early swelling would be, like glutamate-induced neuroexcitation, substantially mediated by non-NMDA receptors and thus relatively resistant to blockade by $\mathrm{APV}$.

In fact, $1 \mathrm{~mm}$ APV produced little reduction in acute glutamate-induced neuronal swelling (Fig. 4, $A, B$ ), while completely blocking the similar acute neuronal swelling produced by exposure to $500 \mu \mathrm{M}$ NMDA (Fig. 4, $C, D$ ). This effect, and the similar action of $2 \mathrm{mM}$ D-APV, was quantitatively documented by morphometrical determination of the mean increase in neuronal cell area seen in a series of neurons acutely following neurotoxic exposure (see Materials and Methods; Fig. 5).

A $5 \mathrm{~min}$ exposure to $500 \mu \mathrm{M}$ concentrations of either NMDA or QUIS produced widespread neuronal cell loss by the follow- 

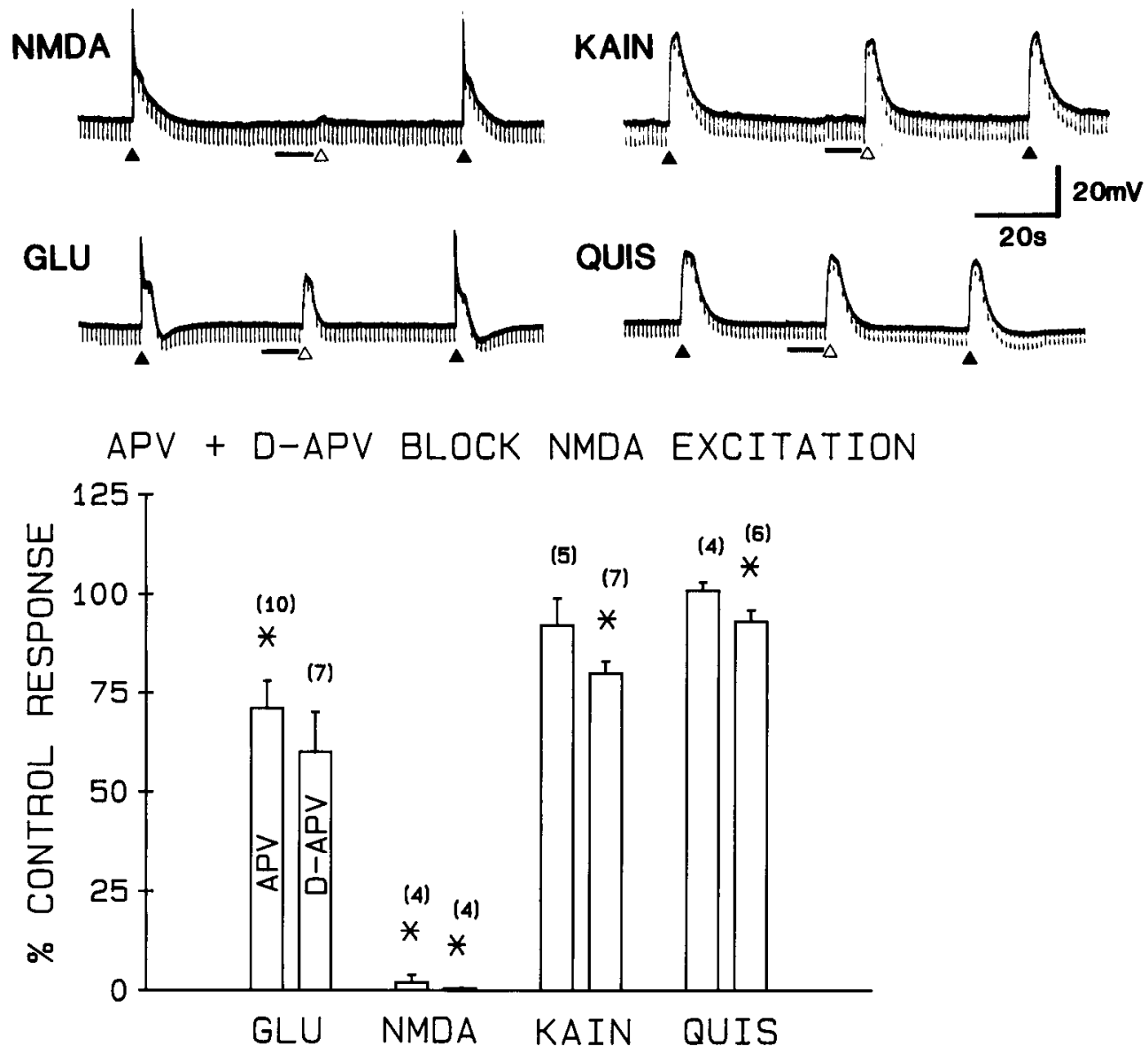

Figure 3. APV blocks NMDA-mediated neuroexcitation. Top, Representative intracellular recordings from 4 cortical neurons show agonist responses (arrows) elicited by pressure ejection before, immediately after, and approximately $30 \mathrm{sec}$ after pressure ejection of $1 \mathrm{~mm}$ APV (horizontal bar). The agonist pulse delivered immediately after ejection of APV (open arrows) was itself mixed with 1 mM APV and thus did not reduce the local concentration of APV. Downward deflections at $1 \mathrm{sec}$ intervals were produced by injection of constant hyperpolarizing current pulses through the recording electrode via a bridge circuit ( $60 \mathrm{msec}$ in duration); the size of the deflections thus reflects cell membrane conductance. The membrane changes induced by $500 \mu \mathrm{M}$ NMDA, but not $50 \mu \mathrm{M}$ QUIS or $500 \mu \mathrm{M}$ KAIN, were reversibly attenuated by APV. Note the early, rapidly decaying component of the NMDA response, which was not seen with KAIN or QUIS responses. APV eliminated this component from the glutamate (GLU) response, but the remainder of the glutamate response was not blocked by APV. Resting potentials were all between -60 and $-70 \mathrm{mV}$. Bottom, Bar graph showing mean + SEM (numbers of cells in parentheses) agonist depolarization amplitude elicited immediately after application of $1 \mathrm{~mm}$ APV (left bar) or $2 \mathrm{~mm}$ D-APV (right bar), expressed as percentage of the control depolarization amplitude in the same neuron using the same experimental paradigm as in above. Both antagonists showed selective activity against NMDA responses, with complete elimination of NMDA responses produced by $2 \mathrm{mM}$ D-APV; considerable glutamate neuroexcitation persisted with both antagonists. The asterisk indicates significant difference $(p<0.05)$ from control (2-tailed $t$ test with Bonferroni correction for 8 comparisons).

ing day, similar to that seen with glutamate. As previously reported, such exposure to KAIN produced loss of only a small number of neurons (Choi et al., 1987a); however, $24 \mathrm{hr}$ exposure to $100 \mu \mathrm{M}$ kainate did result in substantial neuronal loss. The selectivity of 2 mM D-APV was further examined with respect to agonist-induced neurotoxicity, and D-APV was found to selectively block the neuronal cell loss induced by exposure to glutamate and NMDA but not to QUIS or KAIN (Fig. 6).

These experiments suggested that both APV and D-APV remained reasonably selective for NMDA receptor-mediated phenomena at millimolar concentrations, supporting the implication that GNT may be dominated by NMDA receptor activation. However, it remained curious that so little protective effect was seen with lower concentrations of those antagonists, presumably capable of blocking a portion of the NMDA receptor population. The steepness of the concentration-effect relation seen with acute addition of both APV and D-APV suggested that the relationship between NMDA receptor activation and resultant neuronal cell loss, might be nonlinear, i.e., that activation of a relatively small fraction of the NMDA receptor population might ultimately be sufficient to produce substantial neuronal injury.

Such a nonlinearity could be attractively explained if small amounts of acute neuronal injury were compounded by the release of endogenous excitotoxins (glutamate or related compounds) from injured neurons. Direct support for this possibility was provided by Rothman's recent finding that the addition of APV to hippocampal cultures after completion of glutamate exposure, produced an improvement in neuronal survival (Rothman et al., 1986). We were able to confirm Rothman's finding in the cortical cultures: "late" addition of 10-1000 $\mu \mathrm{M}$ concentrations of APV or D-APV to the culture medium shortly after termination of glutamate exposure produced a substantial reduction in GNT that was not mimicked by $1-2 \mu \mathrm{M}$ TTX (Fig. 7). The washout of exogenously added glutamate $(>10,000$-fold dilution) was adequate to eliminate the possibility that this delayed protective effect was due to the antagonism of residual 

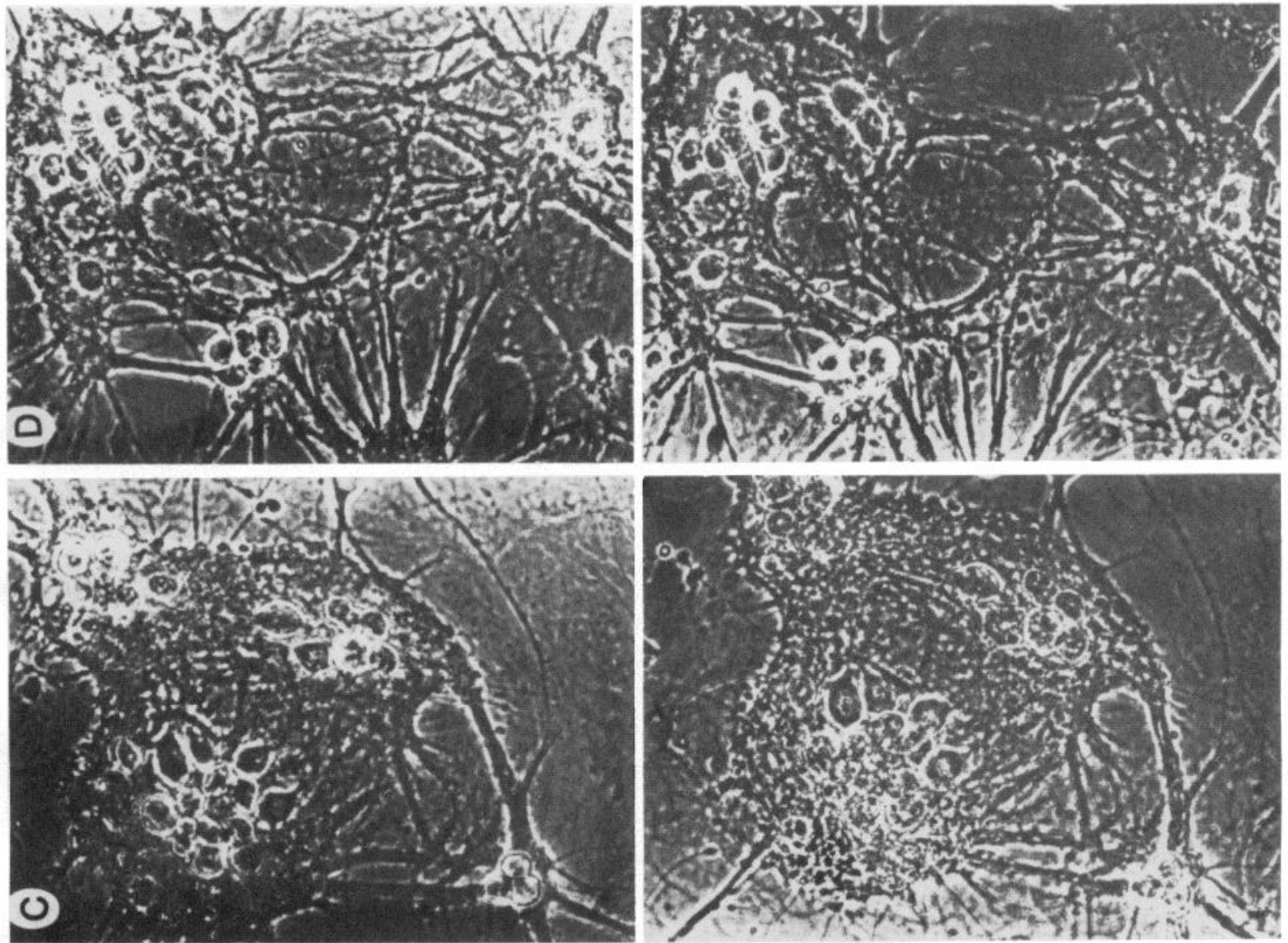

¿

으를

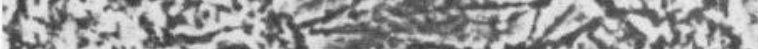

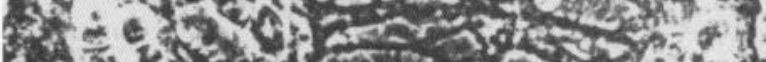

rese

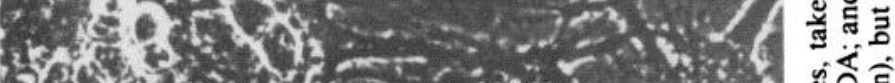

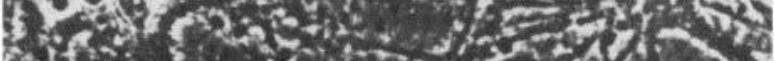

幽於

츨

जั융

$\bar{B} C$

学定

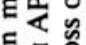

르을

으음

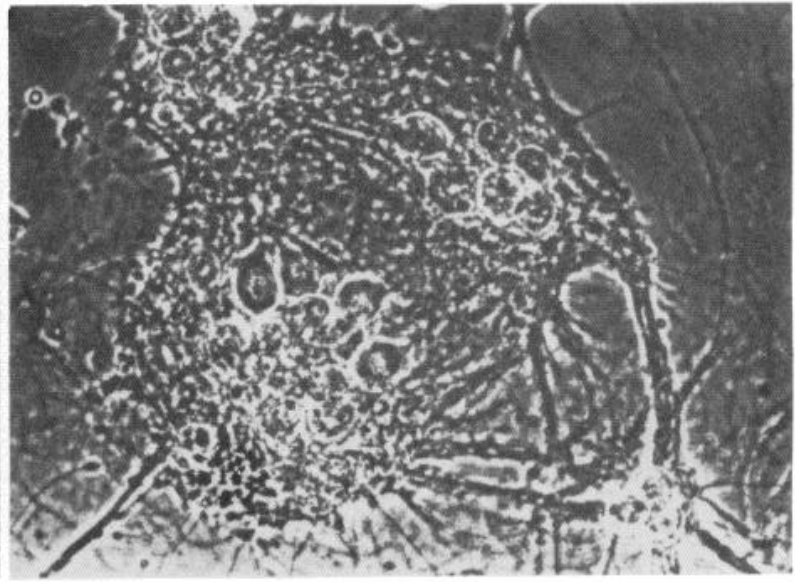

要穷
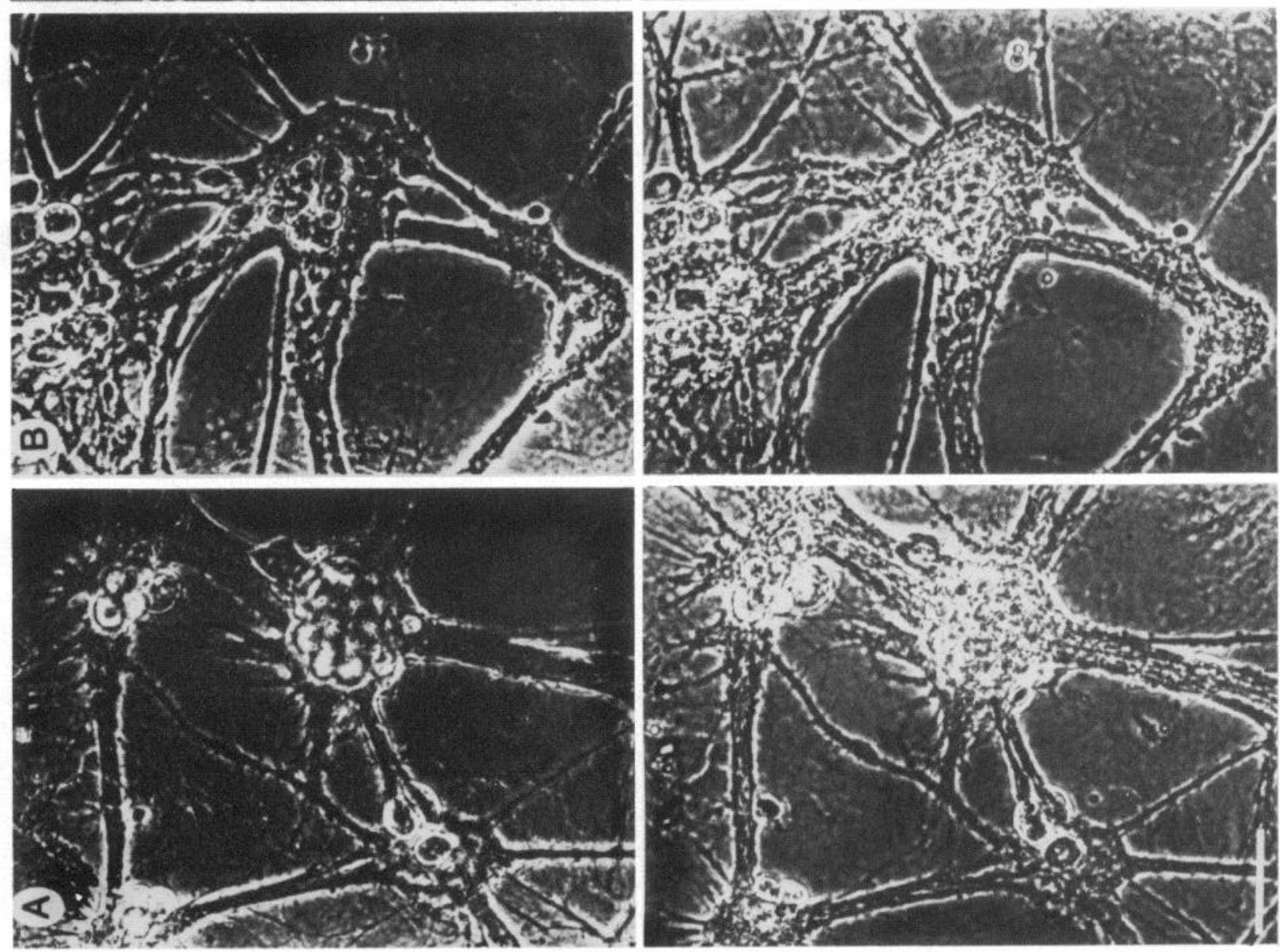

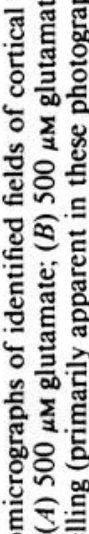

政

을

용

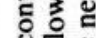

후웜

记

空总

政

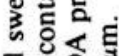

สี้

茫

呵

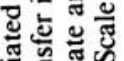

을 है

एक क्षे

을

$\sum \equiv$

4 운

응

入

떠

ट्टे 的 促 可 ن令文 硋 


\section{BEFORE}

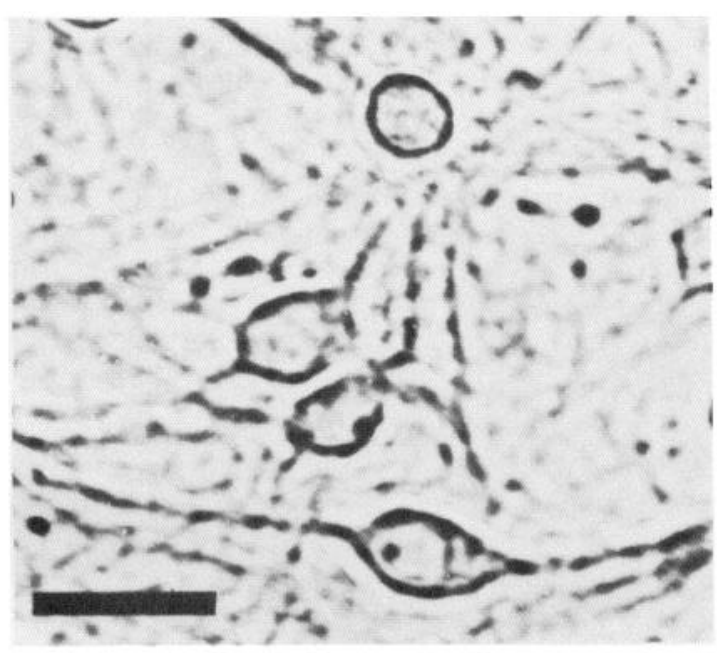

\section{AFTER GLU}

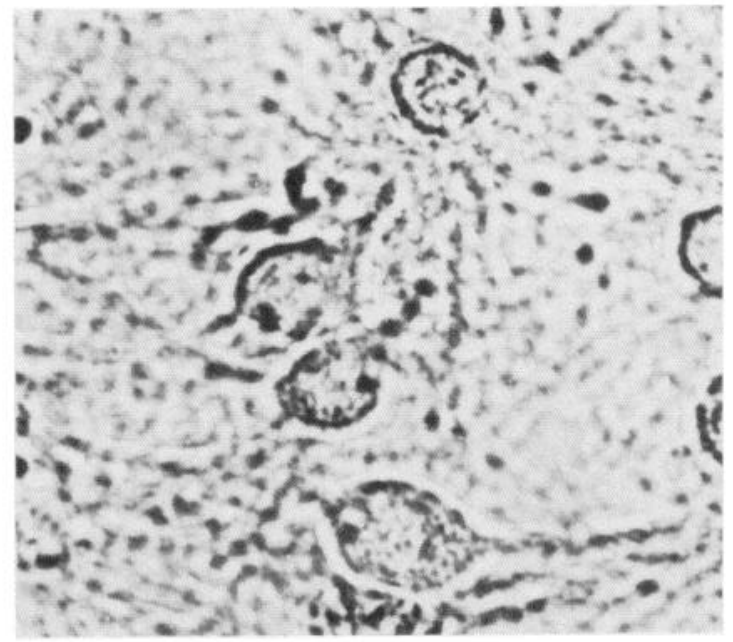

APV \& D-APV VS NEURONAL SWELLING

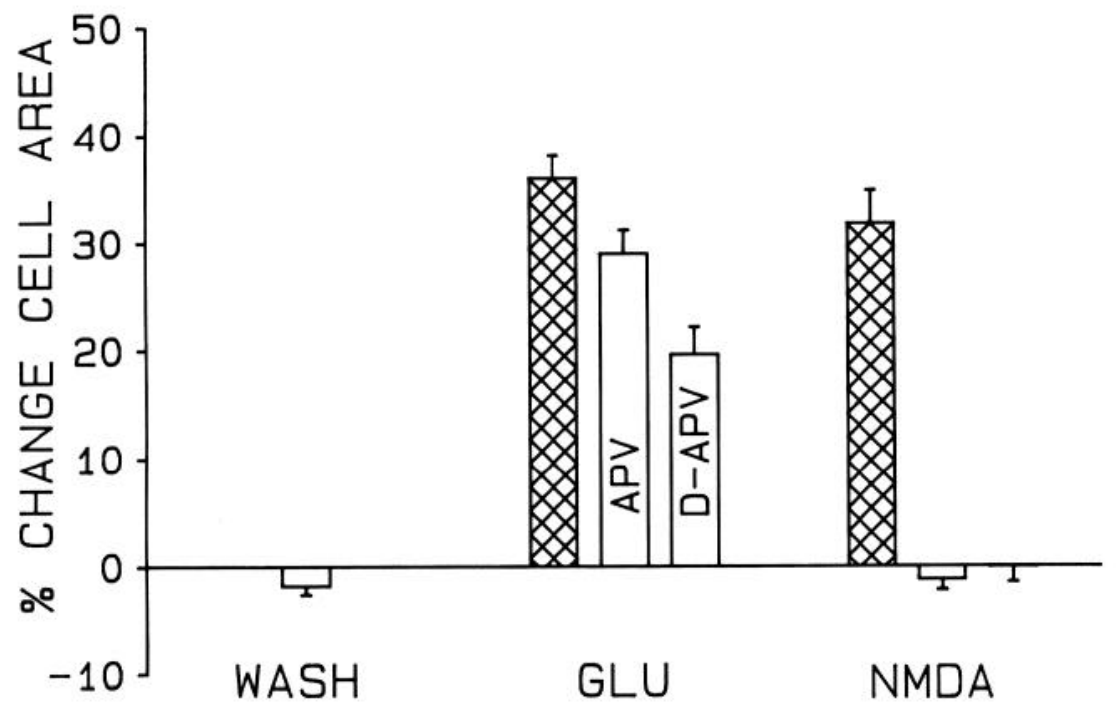

Figure 5. Effect of APV on measured neuronal swelling. Top, Representative bright-field micrographs of several identified cortical neurons are shown before and after exposure to $500 \mu \mathrm{M}$ glutamate for approximately $20 \mathrm{~min}$. Scale bar, $25 \mu \mathrm{m}$. Bottom, Percentage change in the area of cortical neurons on photomicrographs (see Materials and Methods), 15-30 min after the following manipulations: WASH, wash control only; $G L U$, shaded bar, transfer into $500 \mu \mathrm{M}$ glutamate; left open bar, same but $1 \mathrm{mM}$ APV added; right open bar, same but 2 mM D-APV added; $N M D A$, shaded bar, transfer into $500 \mu \mathrm{M}$ NMDA; left open bar, same but $1 \mathrm{~mm}$ APV added; right open bar, same but 2 mM D-APV added. Both glutamate and NMDA induced a marked acute increase in neuronal size, but only the NMDA-induced increase was completely blocked by APV or D-APV. glutamate; a further increase in the washout to 140,000 -fold dilution produced no reduction in GNT.

If D-APV was added both acutely, during the $5 \mathrm{~min}$ glutamate exposure, and late, subsequent to the exposure until assessment of the cultures $1 \mathrm{~d}$ later, an additive protective effect was observed, with substantial protection in the micromolar range, and near complete protection at $1 \mathrm{~mm}$ (Fig. 8); a similar effect was seen with APV (not shown).

Screening tests were performed to determine the ability of a number of other excitatory amino acid antagonists to antagonize GNT acutely (Fig. 9). The selective NMDA antagonist ketamine (KET) (Anis et al., 1983) completely blocked GNT when added at $100 \mu \mathrm{M}-1 \mathrm{~mm}$ during the glutamate exposure, and a substantial protective effect was seen with another NMDA antagonist, 1 mм APH (Evans et al., 1982). The broad-spectrum antagonist KYN (Ganong et al., 1983; Jahr and Jessel, 1985) at $1 \mathrm{~mm}$ also blocked GNT. Lesser but significant protective effects were seen with $1 \mathrm{~mm}$ APB, $1 \mathrm{~mm}$ DAA, $3 \mathrm{~mm}$ DGG, and $3 \mathrm{~mm}$ PDA. In contrast, the antagonist GAMS, which may preferentially block non-NMDA receptors (Davies et al., 1985), was ineffective against GNT, as were $1 \mathrm{~mm}$ concentrations of GDEE, APP, DGG, or PDA. Control experiments documented that all these antagonists, with the sole exception of PDA, lacked intrinsic neurotoxicity over the tested $5 \mathrm{~min}$ exposure. Exposure to $3 \mathrm{~mm}$ PDA alone did produce a small amount of neuronal damage, but not enough to obscure the suggestion of some net protective efficacy against GNT (Fig. 9).

\section{Discussion}

The central finding of the present study is that pharmacological antagonism of the NMDA subclass of glutamate receptors can substantially attenuate late glutamate-induced neuronal loss, out of proportion to attenuation of glutamate neuroexcitation or acute glutamate-induced neuronal swelling. This finding is consistent with the working hypothesis that NMDA receptors mediate most of the ultimate neurotoxicity-i.e., late neuronal loss- 


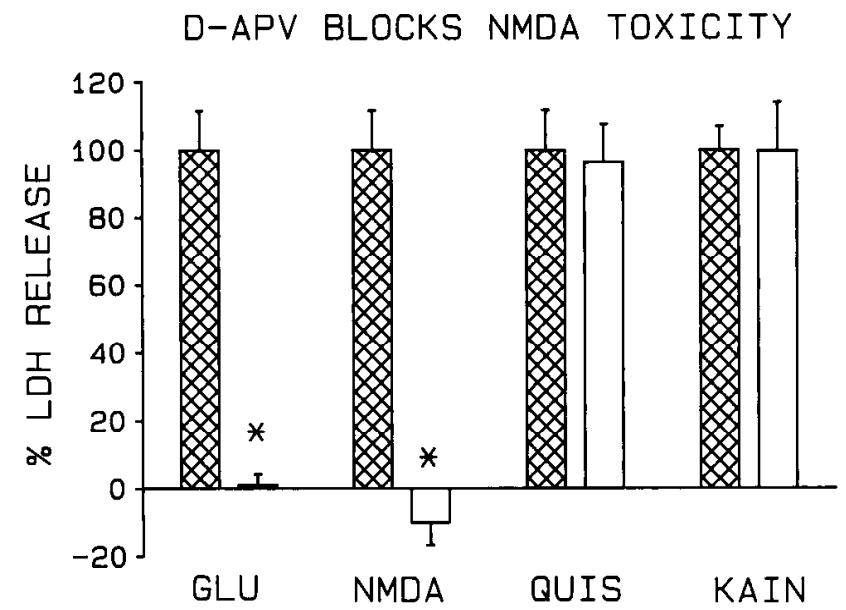

Figure 6. Selectivity of D-APV as an antagonist of NMDA-mediated neurotoxicity. Matched cultures were exposed to GLU (500 $\mu \mathrm{M}$ for 5 min), NMDA ( $500 \mu \mathrm{M}$ for $5 \mathrm{~min})$, KAIN $(100 \mu \mathrm{M}$ for $24 \mathrm{hr})$, or QUIS ( $500 \mu \mathrm{M}$ for $5 \mathrm{~min}$ ) either alone (shaded bars) or with the acute addition of $2 \mathrm{mM}$ D-APV to the exposure solution (unshaded bars). Subsequent neuronal injury or loss was quantitated by the appearance of LDH in the bathing medium (mean $\pm \mathrm{SEM}, n=5$ ) $24 \mathrm{hr}$ after toxic exposure onset. Addition of APV markedly attenuated the ncurotoxicity of GLU and NMDA, but not KAIN or QUIS. Long exposure to KAIN was necessary to produce substantial neuronal injury; other control experiments documented the lack of toxicity of exposure to $2 \mathrm{mM} \mathrm{D}-\mathrm{APV}$ alone for $24 \mathrm{hr}$. The asterisks indicate significant differences $(p<0.005)$ from control (2-tail $t$ test with Bonferroni correction for multiple comparisons).

associated with brief exposure to glutamate, at least on most of the neuronal population (but see Koh et al., 1986). A similar dissociation between neuronal cell loss and acute neuronal swelling was previously demonstrated by manipulations of extracellular cations: Removal of extracellular calcium selectively reduced the former, while replacement of extracellular sodium selectively reduced the latter (Choi, 1987).

The primary pharmacological tools used here were the established NMDA antagonist APV and its purified D-isomer, D-APV. No qualitative differences were seen between APV and D-APV, although D-APV was slightly more effective than APV at high concentrations. Our observations are thus consistent with the suggestion that D-APV is the active component in APV (Stone et al., 1981; Davies and Watkins, 1982). Both drugs were, as expected, reasonably selective antagonists of NMDA neuroexcitation on cortical neurons, but we found here that neither drug was absolutely selective at low millimolar concentrations. In a fashion reminiscent of the ability of high concentrations of strychnine to produce some attenuation of GABA responses (Choi and Fischbach, 1981), 2 mM D-APV not only eliminated NMDA responses, but also produced a $20 \%$ mean reduction in KAIN responses and a 7\% mean reduction in QUIS responses. APV, $1 \mathrm{~mm}$, containing $0.5 \mathrm{~mm} \mathrm{D-APV}$ and able to virtually eliminate NMDA responses ( $98 \%$ mean reduction), produced a $7 \%$ mean reduction in KAIN responses but no reduction in QUIS responscs.

This modest degree of nonselective crossover may have contributed somewhat to the observed acute protective efficacy of saturating concentrations of APV or D-APV against GNT, but the importance of that contribution is likely to be small. D-APV, $2 \mathrm{~mm}$, completely eliminated NMDA neurotoxicity but produced no detectable protection against the direct neurotoxicity of QUIS or KAIN. In addition, these antagonist concentrations produced only the expected partial $(29-40 \%)$ reduction in the mean peak amplitude of the membrane response to $500 \mu \mathrm{M}$ glutamate. A similar $38 \%$ reduction in glutamate-induced current has been reported for $1 \mathrm{~mm}$ APV on chick motoneurons (O'Brien and Fischbach, 1986). Since the component of the glutamate response sensitive to APV, like the response to NMDA itself, often exhibited a rapid decay not seen with QUIS or KAIN responses (see Fig. 3), the measured reductions in peak response might overestimate the actual reductions in the net cation influx induced by prolonged glutamate exposure.

Furthermore, these high concentrations of APV and D-APV also only partially reduced the acute excitotoxic neuronal swelling produced by glutamate. While alterations in neuronal swelling were difficult to appreciate upon simple visual inspection of cultures, quantitative measurement of the acute increase in cell area on photomicrographs produced a reliable index of the swelling. Exposure to $500 \mu \mathrm{M}$ glutamate produced within minutes an acute mean increase in neuronal cell area of $36 \%$, corresponding to a $59 \%$ increase in cell volume (assuming spherical cells); similar neuronal cell swelling was produced by equimolar NMDA exposure. APV, $1 \mathrm{mM}$, or D-APV, $2 \mathrm{mM}$, completely eliminated NMDA-induced swelling, but reduced the glutamate-induced swelling by only 19 or $45 \%$, respectively.

The observed concentration-protection relationship for acute APV or D-APV was steep, with rapid loss of protective efficacy at concentrations below the millimolar concentrations presumably required to competitively antagonize exposure to exogenously added $500 \mu \mathrm{M}$ glutamate. Although the binding data of Olverman et al. (1984) suggest that the affinity of glutamate for D-APV binding sites approaches that of D-APV itself, we think it likely that these high concentrations of APV or D-APV effectively blocked $500 \mu \mathrm{M}$ glutamate from activating most of the physiologically relevant NMDA receptors. O'Brien and Fischbach (1986) found $1 \mathrm{~mm}$ APV to be sufficient to eliminate the voltage-dependent component of the response to $1 \mathrm{~mm}$ glutamate on chick spinal motoneurons. Furthermore, the reductions in glutamate response amplitude produced by APV or D-APV here $(29-40 \%)$ are similar to those produced by pressure ejection of a gross excess concentration ( $2 \mathrm{~mm}$ ) of the noncompetitive inhibitor KET (36 $\pm 11 \% \mathrm{SEM}, n=5$; S. Peters and D. W. Choi, unpublished observations).

While a number of explanations could account for the relative failure of subsaturating concentrations of APV or D-APV to protect neurons against exogenous glutamate, we favor the possibility, discussed above, that neurons only partially protected by the acute addition of APV or D-APV might subsequently become lethally injured by the late release of endogenous NMDA agonist(s). This late release could occur both synaptically, from calcium-loaded and perhaps depolarized neurons, and nonsynaptically, from neurons damaged badly enough to "leak" excitatory amino acids. Supporting evidence for such a sequence is provided by the finding, originally made by Rothman et al. (1986), that a portion of GNT can be blocked by the delayed introduction of APV or D-APV. The sequence is also supported by the observation that TTX did not substitute for APV in producing delayed neuronal protection. The ineffectiveness of TTX suggests specifically that the process responsible for delayed neurotoxicity does not require action potential generation, and is thus probably unrelated to the simple metabolic load of spontaneous neuronal circuit activity. 
CTRL

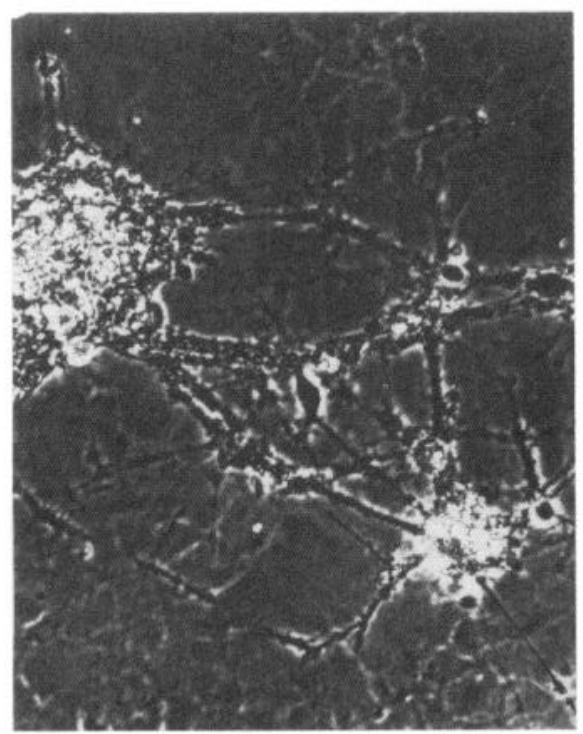

APV

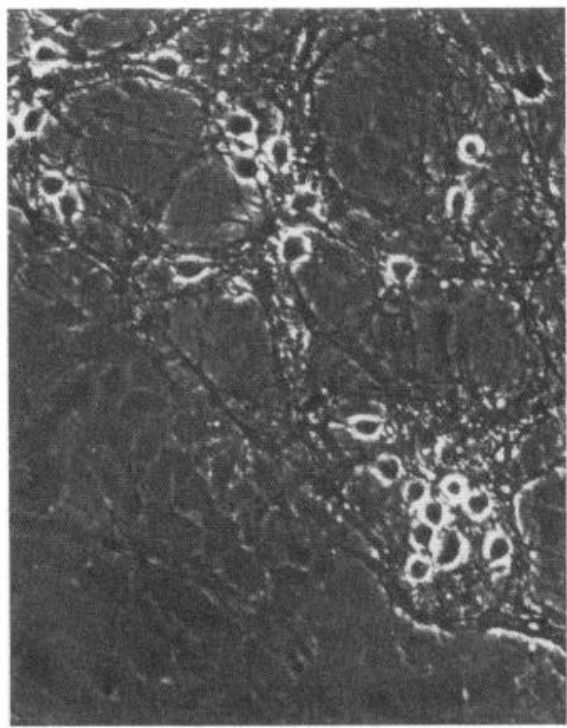

TTX

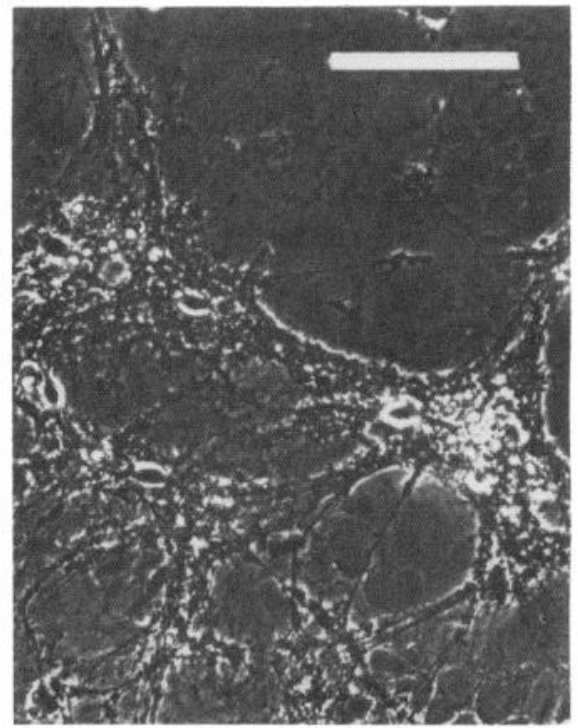

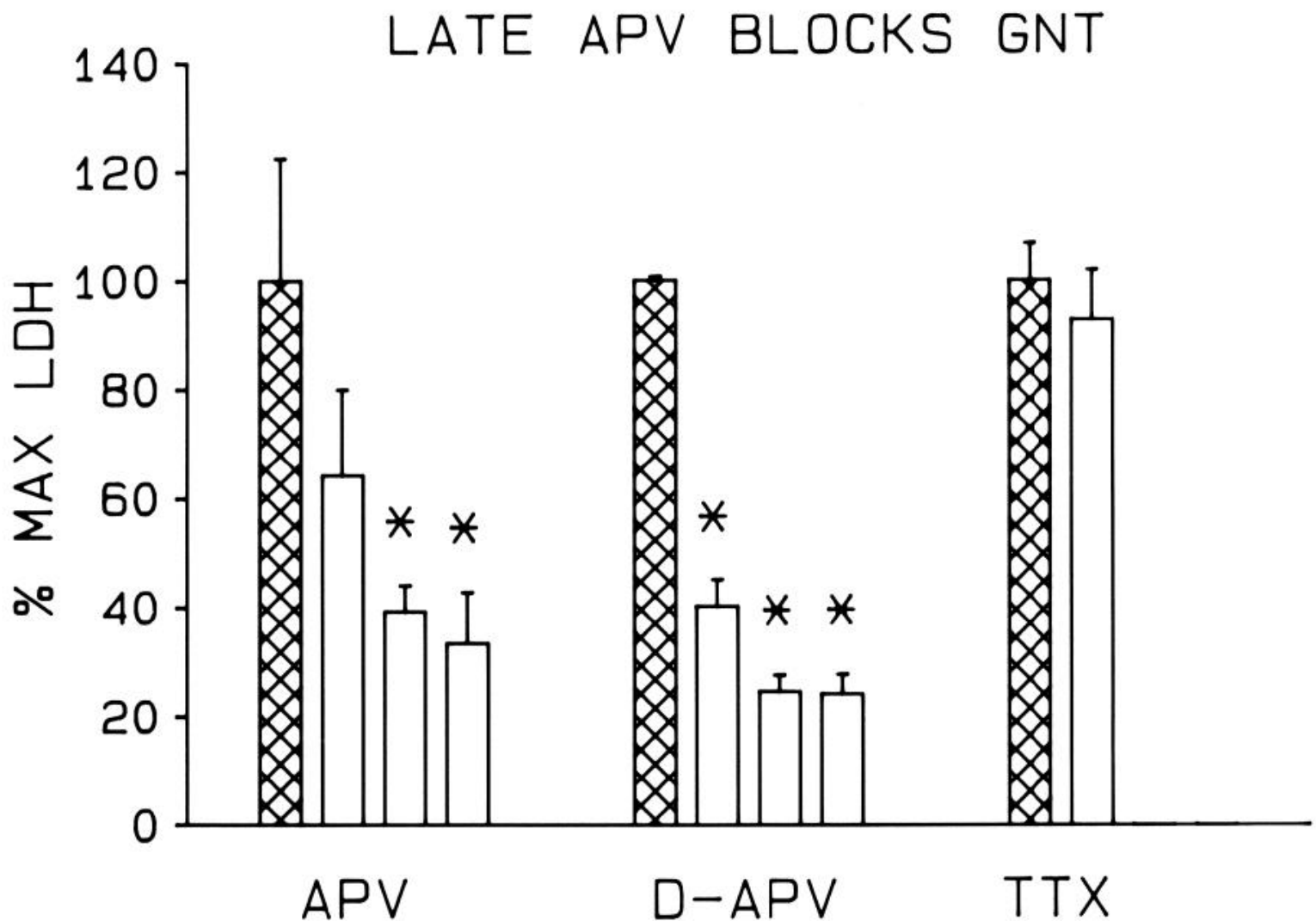

Figure 7. APV attenuates glutamate neurotoxicity even when added "late." Top, Representative phase-contrast micrographs are shown from 3 sister dishes, $1 \mathrm{~d}$ after exposure to $500 \mu \mathrm{M}$ glutamate for $5 \mathrm{~min}$ (CTRL), the same but with $1 \mathrm{~mm}$ APV added after the glutamate exposure ( $A P V$ ), and the same but with $1 \mu \mathrm{M}$ TTX added both during and after the glutamate exposure (TTX). Scale bar, $100 \mu \mathrm{m}$. Bottom, Bars show the amount of LDH present in the medium of cultures $1 \mathrm{~d}$ after exposure to $500 \mu \mathrm{M}$ glutamate for 5 min (mean $+\mathrm{SEM}$ ). In the leftmost group of bars ( $A P V$ ), the shaded bar shows results obtained with control (untreated) cultures, and the 3 open bars show results obtained in matched sister cultures where $10 \mu \mathrm{M}, 100 \mu \mathrm{M}$, or $1 \mathrm{mM}$ (left to right) APV was added after glutamate washout ( $n=3$ for each condition). The middle group of bars (D-APV) similarly shows the results of another experiment performed in identical fashion, but with the addition of D-APV $(n=4)$. The right pair of bars shows, for comparison, the minimal change seen with the addition of 1-2 $\mu \mathrm{M}$ TTX, both during and after glutamate exposure (shaded bar, control; open bar, TTX added, $n=8)$. The asterisks indicate significant differences $(p<0.05)$ compared with control (analysis of variance with application of Fisher's least-significant difference test). 


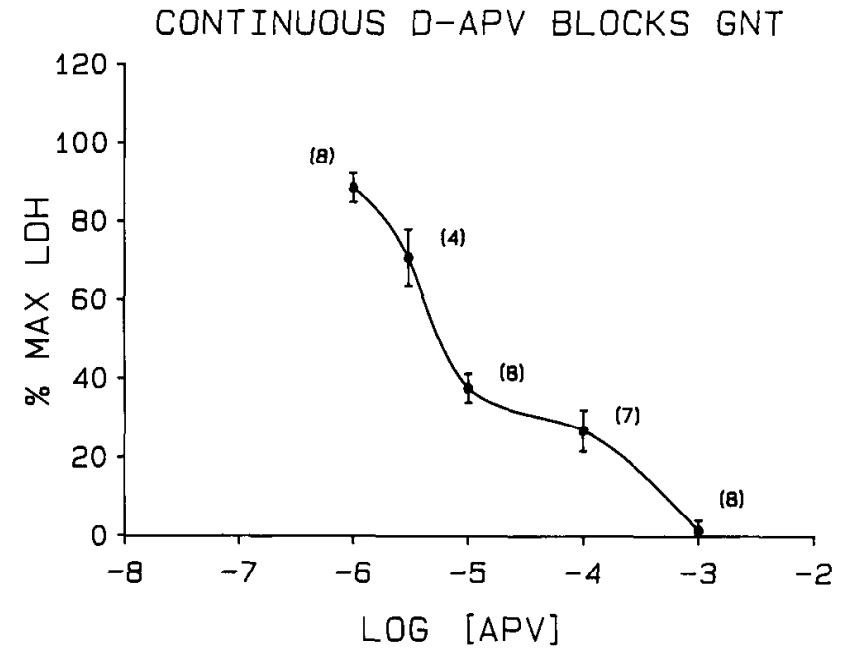

Figure 8. Continuous D-APV dose-protection relationship. Cultures were exposed to $500 \mu \mathrm{M}$ glutamate for $5 \mathrm{~min}$, with the indicated concentrations of D-APV present both during and after the glutamate exposure. The amount of LDH present in the bathing medium the following day is shown (mean \pm SEM, number of cultures specified in parentheses for each point). A substantial protective effect is evident at micromolar concentrations of D-APV.

Several neurotoxic NMDA agonists are endogenous to cortical neurons and could contribute to delayed neurotoxicity: Present results suggest that glutamate itself would be a strong candidate, but other compounds would include aspartate, quinolinate (Schwarcz et al., 1983), homocysteate (Do et al., 1986), and $N$-acetylaspartylglutamate (Westbrook et al., 1986). Only 10-100 $\mu \mathrm{M}$ concentrations of APV/D-APV were required to produce a late neuron-protective effect, probably because the effective concentration of endogenously released neurotoxic

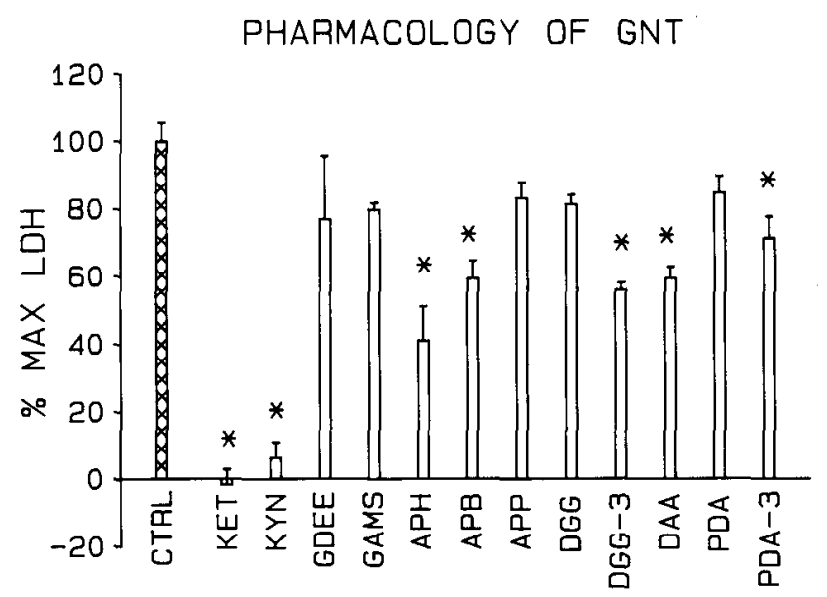

Figure 9. Ability of several excitatory amino acid antagonists to block chemical evidence of glutamate neurotoxicity. Open bars show the amount of LDH present in the medium of cultures $1 \mathrm{~d}$ after exposure to $500 \mu \mathrm{M}$ glutamate for $5 \mathrm{~min}$, in the presence of the indicated antagonist (see text for key to abbreviations). The shaded bar shows results obtained with a single set of representative control (untreated) cultures; other similar controls used to normalize some of the drug trials displayed here are not shown. All antagonists were present acutely at $1 \mathrm{~mm}$, except for KET $(100 \mu \mathrm{M})$; PDA and DGG were tested at both $3 \mathrm{~mm}$ (3 suffix) and $1 \mathrm{~mm}$. The asterisks indicate significant differences $(p<0.05)$ compared with appropriate control (analysis of variance and Student-Newman-Keuls' test).

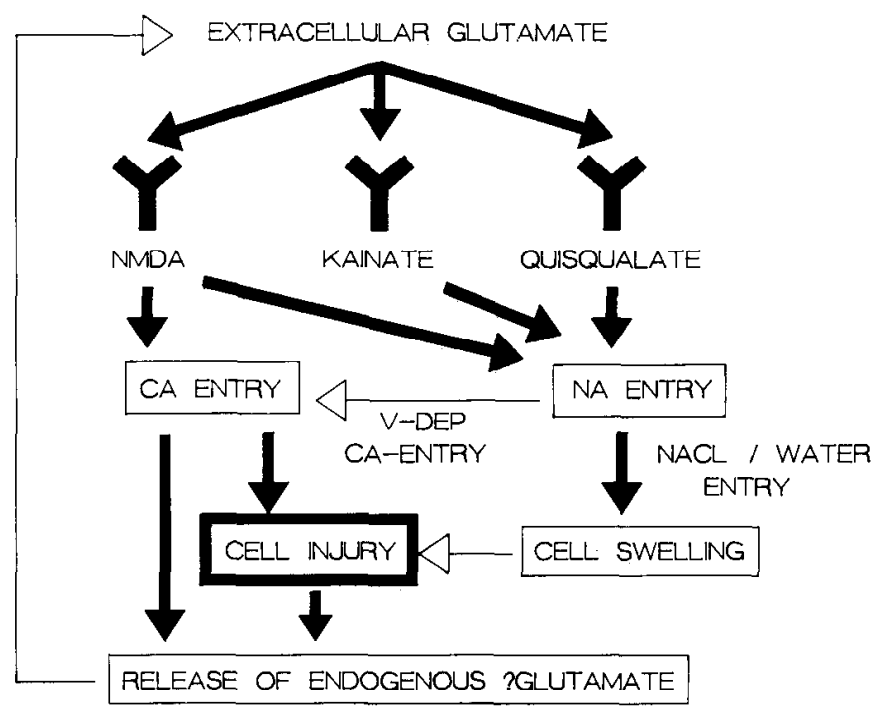

Figure 10. Partial model for glutamate neurotoxicity.

NMDA agonists was lower (and hence more easily blocked) than the $500 \mu \mathrm{M}$ of added exogenous glutamate.

When APV/D-APV were added both during and after glutamate exposure ("continuous" antagonist), thus blocking NMDA receptors from activation either by exogenous glutamate or by subsequently released endogenous excitotoxins, a summation dose-protection relationship was obtained. Although concentrations near $1 \mathrm{~mm}$ were still required to eliminate GNT, halfprotection could be obtained with concentrations in the range of several micromoles.

The hypothesis that NMDA receptors predominantly mediate GNT was further supported by the results of screening high concentrations of a number of excitatory amino acid antagonists against GNT. The "acute" experimental paradigm was chosen for 2 reasons: (1) to minimize difficulty with any intrinsic neurotoxicity (partial agonist effect) of the antagonists; and (2) to improve discrimination, as the results with APV/D-APV suggested that relatively small amounts of NMDA receptor antagonism in the "late" paradigm might produce detectable neuron protection. The drugs which reduced glutamate-induced neuronal injury by $50 \%$ or more were $100 \mu \mathrm{m}$ ketamine, $1 \mathrm{~mm} \mathrm{APH,}$ and $1 \mathrm{~mm}$ KYN-drugs known to antagonize NMDA neuroexcitation substantially in other systems (see above). Some protection against GNT was conveyed by $1 \mathrm{~mm}$ APB, 1 mм DAA, $3 \mathrm{~mm}$ DGG, and $3 \mathrm{~mm}$ PDA, drugs generally considered to have some antagonist efficacy on NMDA responses (Davies et al., 1981). At least at $1 \mathrm{~mm}$ concentrations, GDEE, GAMS, and APP-drugs with little reported ability to block NMDA neuroexcitation - were ineffective in blocking GNT. Consistent with this antagonist profile for GNT, the potent selective NMDA antagonist dextrorphan (Church et al., 1985; Choi et al., 1987b) could also substantially attenuate glutamate neurotoxicity (Choi ct al., 1987b).

The present study has 3 implications of note. First, the study creates a bridge between the specific notion that endogenous glutamate is involved in certain forms of acute central neuronal injury and the growing body of experimental evidence showing that selective blockade of NMDA receptors alone can dramatically attenuate such injury both in vitro (Goldberg et al., 1986; Weiss et al., 1986) and in vivo (Simon et al., 1984; Wieloch, 
1985). While the simultaneous participation of other endogenous NMDA agonists (see above) in excitotoxic brain injury is probable, the vast amount of glutamate available in the mammalian brain conveys a uniquely high potential for pathogenesis.

Second, given the evidence cited above suggesting that the NMDA channel has a much higher calcium permeability than KAIN or QUIS channels, the present study provides some pharmacological support for the hypothesis that GNT is largely mediated by a calcium influx (Choi, 1985). While both KAIN and QUIS depolarize neurons and would therefore trigger some indirect calcium influx through voltage-dependent channels, 2 arguments suggest that this source of calcium entry may be less important than the calcium entering directly through NMDA channels: (1) Magnesium, $20 \mathrm{~mm}$, which should block voltagedependent calcium channels, does not have much effect on GNT (Choi, 1987). [In the presence of normal extracellular sodium, magnesium blockade of NMDA channels would be relieved by non-NMDA receptor-mediated membrane depolarization; if sodium is replaced by choline, then magnesium does block GNT (Choi, 1987).] (2) Kainate, while a potent neuroexcitant, is a weak neurotoxin (Choi et al., 1987a), requiring prolonged exposure to destroy a majority of cortical neurons (see Fig. 7). Of course, both of these arguments against a major role of voltagedependent calcium channels in mediating glutamate neurotoxicity are oblique; proper understanding of that role will depend on eventual direct experimental tests. Also, the observed high efficacy of QUIS as a rapid-acting neurotoxin is an unexplained finding appropriate for future investigation. QUIS neurotoxicity might, for example, be mediated by direct activation of inositol phospholipid metabolism and mobilization of intracellular calcium (Sugiyama et al., 1987).

Finally, the present study has implications for the development of new therapeutic approaches to reducing brain injury in man. While NMDA receptor blockade is already a strategy of some proven protective efficacy in experimental models, our results are consistent with the implication that glutamate itself is a dominant toxic agonist at the NMDA receptor; thus, they raise the possibility that maneuvers specifically directed toward reducing pathological glutamate accumulation - e.g., decreasing glutamate synthesis or increasing cellular uptake of glutamatemay prove likewise efficacious. Furthermore, the finding that glutamate-induced neuronal injury can be reduced, after exposure, by the late introduction of micromolar concentrations of NMDA receptor antagonists, could eventually have profound implications in the clinical arena, where intervention often must lag behind insult.

In summary, we propose a skeleton model of GNT consistent with studies to date, in the hope that it will be heuristically useful in future studies (Fig. 10). We acknowledge that the model is oversimplified and likely incomplete; among other shortcomings, it includes no mention of potentially important secondmessenger processes or receptor regulatory mechanisms. In the model, glutamate activates both NMDA, and non-NMDA (KAIN and QUIS) receptors. Activation of both NMDA and non-NMDA receptors leads to a sodium influx, producing depolarization, excitotoxic cell swelling (after secondary influx of more sodium, chloride, and water), and some calcium influx through voltage-dependent channels. However, only activation of NMDA receptors opens channels with high intrinsic calcium permeability, and thus leads to a substantial calcium influx. Neuronal cell injury results mainly from elevated intracellular calcium but also partly from excitotoxic cell swelling. Because of some combination of cell injury and calcium-evoked synaptic mechanisms, intracellular pools of NMDA agonists (perhaps in large part glutamate) are released to the immediate environment, and over time feed back on neuronal NMDA receptors to produce progressive neuronal injury.

\section{References}

Anis, N. A., S. C. Berry, N. R. Burton, and D. Lodge (1983) The dissociative anaesthetics, ketamine and phencyclidine, selectively reduce excitation of central mammalian neurones by N-methyl-aspartate. Br. J. Pharmacol. 79: 565-575.

Benveniste, H., J. Drejer, A. Schousboe, and N. H. Diemer (1984) Elevation of the extracellular concentrations of glutamate and aspartate in rat hippocampus during transient cerebral ischcmia monitored by intracerebral microdialysis. J. Neurochem. 43: 1369-1374.

Choi, D. W. (1985) Glutamate neurotoxicity in cortical cell culture is calcium dependent. Neurosci. Lett. 58: 293-297.

Choi, D. W. (1987) Ionic dependence of glutamate neurotoxicity in cortical cell culture. J. Neurosci. 7: 369-379.

Choi, D. W., and G. D. Fischbach (1981) GABA conductance of chick spinal cord and dorsal root ganglion neurons in cell culture. J. Neurophysiol. 45: 605-620.

Choi, D. W., S. Peters, and M. Yokoyama (1986) Glutamate neurotoxicity in cortical cell culture is attenuated by N-methyl-D-aspartate receptor antagonists. Soc. Neurosci. Abstr. 12: 381.

Choi, D. W., M. A. Maulucci-Gedde, and A. R. Kriegstein (1987a) Glutamate neurotoxicity in cortical cell culture. J. Neurosci. 7: 357368.

Choi, D. W., S. Peters, and V. Viseskul (1987b) Dextrorphan and levorphanol selectively block N-methyl-D-aspartate receptor-mediated neurotoxicity on cortical neurons. J. Pharmacol. Exp. Ther. 242: 713-720.

Church, J., D. Lodge, and S. C. Berry (1985) Differential effects of dextrorphan and levorphanol on the excitation of rat spinal neurons by amino acids. Eur. J. Pharmacol. 111: 185-190.

Coyle, J. T., S. J. Bird, R. H. Evans, R. L. Gulley, J. V. Nadler, W. J. Nicklas, and J. W. Olney (1981) Excitatory amino acid neurotoxins: Selectivity, specificity, and mechanisms of action. Neurosci. Res. Program Bull. 19: 331-427.

Davies, J., and J. C. Watkins (1982) Actions of D and L forms of 2- amino-5-phosphonovalerate and 2-amino-4-phosphonobutyrate in the cat spinal cord. Brain Res. 235: 378-386.

Davies, J., and J. C. Watkins (1985) Depressant actions of gammaD-glutamylaminomethyl sulfonate (GAMS) on amino acid-induced and synaptic excitation in the cat spinal cord. Brain Res. 327: 113120.

Davies, J., A. A. Francis, A. W. Jones, and J. C. Watkins (1981) 2-Amino-5-phosphonovalerate (2APV), a potent and selective antagonist of amino acid-induced and synaptic excitation. Neurosci. Lett. 21: 77-81.

DeBoni, U., and D. R. McLachlan (1985) Controlled induction of paired helical filaments of the Alzheimer type in cultured human neurons, by glutamate and aspartate. J. Neurol. Sci. 68: 105-118.

Do, K. Q., P. L. Herrling, P. Streit, W. A. Turski, and M. Cuenod (1986) In vitro release and electropyhysiological effects in situ of homocysteic acid, an endogenous $\mathrm{N}$-mcthyl-(D)-aspartic acid agonist, in the mammalian striatum. J. Neurosci. 6: 2226-2234.

Evans, R. H., A. A. Francis, A. W. Jones, D. A. S. Smith, and J. C. Watkins (1982) The effects of a series of omega-phosphonic alphacarboxylic amino acids on electrically evoked and excitant amino acid-induced responses in isolated spinal cord preparations. $\mathrm{Br}$. $\mathbf{J}$. Pharmacol. 75: 65-75.

Foster, A. C., and G. E. Fagg (1984) Acidic amino acid binding sites in mammalian neuronal membranes: Their characteristics and relationship to synaptic receptors. Brain Res. 319: 103-164.

Ganong, A. H., T. H. Lanthorn, and C. W. Cotman (1983) Kynurenic acid inhibits synaptic and acidic amino acid-induced responses in the rat hippocampus and spinal cord. Brain Res. 273: 170-174.

Garthwaite, J. (1985) Cellular uptake disguises action of L-glutamate on N-methyl-D-aspartate receptors. With an appendix: Diffusion of transported amino acids into brain slices. Br. J. Pharmacol. 85: 297307.

Garthwaite, G., and J. Garthwaite (1986) Neurotoxicity of excitatory 
amino acid receptor agonists in rat cerebellar slices: Dependence on calcium concentration. Neurosci. Lett. 66: 193-198.

Goldberg, M. P., J. Weiss, and D. W. Choi (1986) Hypoxic cortical neuronal injury is blocked by $\mathrm{N}$-methyl-D-aspartate receptor antagonists. Soc. Neurosci. Abstr. 12: 64

Hagberg, H., A. Lehmann, M. Sandberg, B. Nystrom, I. Jacobson, and A. Hamberger (1985) Ischemia-induced shift of inhibitory and excitatory amino acids from intra- to extracellular compartments. J. Cereb. Blood Flow Metab. 5: 413-419.

Huettner, J. E., and R. W. Baughman (1986) Primary culture of identified neurons from the visual cortex of postnatal rats. J. Neurosci. 6: 3044-3060.

Jahr, C. E., and T. M. Jessell (1985) Synaptic transmission between dorsal root ganglion and dorsal horn neurons in culture: Antagonism of monosynaptic excitatory postsynaptic potentials and glutamate excitation by kynurenate. J. Neurosci. 5: 2281-2289.

Koh, J. Y., and D. W. Choi (1987) Quantitative determination of glutamate mediated cortical neuronal injury in cell culture by lactate dehydrogenase efflux assay. J. Neurosci. Methods 20: 83-90.

Koh, J. Y., S. Peters, and D. W. Choi (1986) Neurons containing NADPH-diaphorase are selectively resistant to quinolinate toxicity. Science 234: 73-76.

Lucas, D. R., and J. P. Newhouse (1957) The toxic effect of sodium L-glutamate on the inner layers of the retina. Arch. Ophthalmol. 58: 193-201.

MacDermott, A. B., M. L. Mayer, G. L. Westbrook, S. J. Smith, and J. L. Barker (1986) NMDA-receptor activation increases cytoplasmic calcium concentration in cultured spinal cord neurones. Nature 321: 519-522.

Mangano, R. M., and R. Schwarcz (1983) Chronic infusion of endogenous excitatory amino acids into rat striatum and hippocampus. Brain Res. Bull. 10: 47-51.

Mayer, M. L., and G. L. Westbrook (1984) Mixed-agonist action of excitatory amino acids on mouse spinal cord neurones under voltage clamp. J. Physiol. (Lond.) 354: 29-53.

Mayer, M. L., G. L. Westbrook, and P. B. Guthrie (1984) Voltagedependent block by $\mathrm{Mg}^{2+}$ of NMDA responses in spinal cord neurones. Nature 309: 261-263.

Maycr, M. L., A. B. MacDcrmott, G. L. Wcstbrook, A. J. Smith, and J. L. Barker (1986) Calcium transients recorded from mouse spinal cord neurons under voltage-clamp. Soc. Neurosci. Abstr. 12: 1196.

McGeer, E. G., and P. L. McGeer (1976) Duplication of biochemical changes of Huntington's chorea by intrastriatal injections of glutamic and kainic acids. Nature 263: 517-519.

Nadler, J. V., B. W. Perry, and C. W. Cotman (1978) Intraventricular kainic acid preferentially destroys hippocampal pyramidal cells. Nature 271: 676-677.

Nowak, L., P. Bregestovski, P. Ascher, A. Herbet, and A. Prochiantz (1984) Magnesium gates glutamate-activated channels in mouse central neurones. Nature 307: 462-465.

O'Brien, R. J., and G. D. Fischbach (1986) Characterization of excitatory amino acid receptors expressed by embryonic chick motoncurons in vitro. J. Ncurosci. 6: 3275-3283.

Olney, J. W. (1969) Brain lesion, obesity and other disturbances in mice treated with monosodium glutamate. Science 164: 719-721.

Olney, J. W. (1978) Neurotoxicity of excitatory amino acids. In Kainic Acid as a Tool in Neurobiology, E. G. McGeer et al., eds. Raven, New York.

Olney, J. W., and T. De Gubareff (1978) Glutamate neurotoxicity and Huntington's chorea. Nature 271: 557-559.
Olney, J. W., O. L. Ho, and V. Rhee (1971) Cytotoxic effects of acidic and sulphur containing amino acids on the infant mouse central nervous system. Exp. Brain Res. 14: 61-76.

Olney, J. W., R. C. Collins, and R. S. Sloviter (1986) Excitotoxic mechanisms of epileptic brain damage. Adv. Neurol. 44: 857-877.

Olverman, H. J., A. W. Jones, and J. C. Watkins (1984) L-glutamate has higher affinity than other amino acids for [ $\left.{ }^{3} \mathrm{H}\right]-\mathrm{D}-\mathrm{AP} 5$ binding sites in rat brain membranes. Nature 307: 460-462.

Plaitakis, A., S. Berl, and M. D. Yahr (1982) Abnormal glutamate metabolism in an adult-onset degenerative neurological disorder. Science 216: 193-196.

Rothman, S. (1984) Synaptic release of excitatory amino acid neurotransmitter mediates anoxic neuronal death. J. Neurosci. 4: 1884 1891.

Rothman, S. M. (1985) The neurotoxicity of excitatory amino acids is produced by passive chloride influx. J. Neurosci. 5: 1483-1489.

Rothman, S. M., and J. W. Olney (1986) Glutamate and the pathophysiology of hypoxic-ischemic brain damage. Ann. Neurol. 19: 105111.

Rothman, S. M., J. H. Thurston, and R. E. Hauhart (1986) Delayed neurotoxicity of excitatory amino acids depends upon synaptic activity. Soc. Neurosci. Abstr. 12: 380.

Schwarcz, R., and B. Meldrum (1985) Excitatory aminoacid antagonists provide a therapeutic approach to neurological disorders. Lancet 2: $140-143$.

Schwarcz, R., W. O. Whetsell, Jr., and R. M. Mangano (1983) Quinolinic acid: An endogenous metabolite that produces axon-sparing lesions in rat brain. Science 219: 316-318.

Simon, R. P., J. H. Swan, T. Griffiths, and B. S. Meldrum (1984) Blockade of N-methyl-D-aspartate receptors may protect against ischemic damage in the brain. Science 226: 850-852.

Sloviter, R. S. (1983) "Epileptic" brain damage in rats induced by sustained electrical stimulation of the perforant path. I. Acute electrophysiological and light microscopic studies. Brain Res. Bull. 10: 675-697.

Stone, T. W., M. N. Perkins, J. F. Collins, and K. Curry (1981) Activity of the enantiomers of 2-amino-5-phosphono-valeric acid as stereospecific antagonists of excitatory aminoacids. Neuroscience 6: 22492252.

Sugiyama, H., I. Ito, and C. Hirono (1987) A new type of glutamate receptor linked to inositol phospholipid metabolism. Nature 325: 531-533.

Watkins, J. C., and R. H. Evans (1981) Excitatory amino acid transmitters. Annu. Rev. Pharmacol. Toxicol. 21: 165-204.

Weiss, J., M. P. Goldberg, and D. W. Choi (1986) Ketamine protects cultured neocortical neurons from hypoxic injury. Brain Res. 380: 186-190.

Westbrook, G. L., M. L. Mayer, M. A. A. Namboodiri, and J. H. Neale (1986) High concentrations of N-acetylaspartylglutamate (NAAG) selectively activate NMDA receptors on mouse spinal cord neurons in cell culture. J. Neurosci. 6: 3385-3392.

Wieloch, T. (1985) Hypoglycemia-induced neuronal damage prevented by an N-methyl-D-aspartate antagonist. Science $230: 681-$ 683.

Wroblewski, F., and J. S. LaDue (1955) Lactic dehydrogenase activity in blood. Proc. Soc. Exp. Biol. Med. 90: 210-213.

Zorumski, C. F., and G. D. Fischbach (1985) Differentiation between glutamate receptors based on desensitization. Soc. Neurosci. Abstr. 11: 105 . 